\title{
Regulation of AHL Production and Its Contribution to Epiphytic Fitness in Pseudomonas syringae
}

\author{
Beatriz Quiñones, Catherine J. Pujol, and Steven E. Lindow \\ Department of Plant and Microbial Biology, University of California, Berkeley, CA 94720-3102, U.S.A.
}

Submitted 25 September 2003. Accepted 29 November 2003.

\begin{abstract}
Pseudomonas syringae forms large cell aggregates that are more stress tolerant than solitary cells during epiphytic growth on plants. The differential survival of aggregates on leaves suggests that epiphytic fitness traits may be controlled in a density-dependent manner via cell-cell signaling. We investigated this hypothesis in $P$. syringae B728a. Synthesis of $\mathrm{N}$-acyl-homoserine lactone (AHL), 3-oxo-hexanoyl homoserine lactone, and the expression of the gene encoding AHL synthase ahlI were maximal at high cell concentrations. The expression of the AHL regulator ahlR, in contrast, was similar at all cell concentrations. A screen of Tn5 mutants revealed that $P$. syringae $B 728$ a requires a novel transcriptional activator for AHL production. This regulator, which belongs to the TetR family, was also required for epiphytic fitness and has been designated AefR (for AHL and epiphytic fitness regulator). The expression of ahlI was greatly reduced in both $a e f R^{-}$and $g a c A^{-}$mutants and was completely restored in either mutant after addition of exogenous AHL. In contrast, the expression of aefR was not reduced in either gacS $^{-}$or gacA $^{-}$mutants. Thus, AefR appears to positively regulate $A H L$ production independently of the regulators GacS/GacA and also controls traits in $P$. syringae B728a that are required for epiphytic colonization.
\end{abstract}

Additional keywords: acyl-homoserine lactone, AefR, AhlI, AhlR, epiphytic bacteria, quorum sensing.

The surfaces of leaves are capable of supporting large populations of bacterial epiphytes that can affect plant health in various ways. For example, most plant-pathogenic bacteria, such as Pseudomonas syringae pv. syringae, the causal agent of brown spot disease of bean, multiply to large population sizes $\left(10^{7}\right.$ cells per $\left.\mathrm{g}\right)$ on the surface of healthy plants before initiating disease. Large epiphytic populations on healthy leaves always precede disease, and a direct correlation exists between the probability of disease and prior epiphytic population sizes of $P$. syringae (Hirano and Upper 2000; Rouse et al. 1985). The epiphytic phase of this bacterial pathogen is thus considered one of the first steps in the infection process and is a target for the chemical control of disease with bactericides (Beattie and Lindow 1999; Hirano and Upper 2000).

Corresponding author: S. E. Lindow; Telephone: +1.510.642.4174; Fax: +1.510.642.4995; E-mail: icelab@ socrates.berkeley.edu

Current address of C. J. Pujol: Diversa Corporation, 4955 Directors Place, San Diego, CA 92121, U.S.A.

Nucleotide sequence data are available in the EMBL Nucleotide Sequence Database under the accession numbers AJ567455 (ahll), AJ566343 (ahlR), and AJ566342 (aefR).
Epiphytic bacteria do not occur in a uniform or dispersed pattern on the leaf but are preferentially found at certain sites, such as along veins and near trichomes (Beattie and Lindow 1999; Hirano and Upper 2000). Epiphytes can occur in aggregates comprising thousands of cells (Morris et al. 1997, 1998). Quantitative microscopic analysis of epiphytic populations of $P$. syringae pv. syringae $\mathrm{B} 728$ a revealed that many parts of a leaf are sparsely colonized, with bacteria occurring as solitary cells or in small groups ( $<10$ cells per aggregate) (Monier and Lindow 2004). In contrast, a few sites, often at the base of glandular trichomes or near veins, support large bacterial populations ( $>1,000$ cells per aggregate). These large aggregates often account for the majority of the cells on the leaf surface (Monier and Lindow 2004). Importantly, cells in these large aggregates exhibit a greater ability to survive desiccation stress on leaves than more solitary cells (Monier and Lindow 2003). In fact, such stress survival increased with increasing size of bacterial aggregates (Monier and Lindow 2003). Thus, the formation of aggregates on plants appears to be a crucial strategy for successful colonization of the leaf by bacteria such as $P$. syringae.

The fact that the majority of epiphytic bacterial cells reside in large aggregates has many implications for their behavior on leaves. The enhanced survival of $P$. syringae cell aggregates suggests that epiphytic fitness traits may be controlled in a cell density-dependent fashion, as are a variety of traits in other bacteria. Many microbial traits are expressed in a cell densitydependent manner by a process known as quorum sensing (de Kievit and Iglewski 2000; Loh et al. 2002; Miller and Bassler 2001; Pierson et al. 1999; Whitehead et al. 2001). In this process, bacteria sense their population density by detecting the presence of small diffusible signal molecules and responding with changes in gene expression. The best characterized signal molecules are the $N$-acyl-homoserine lactones (AHL) whose production is dependent on homologs of the luxI and luxR genes. The luxI homologs encode an AHL synthase that, in the presence of the cellular metabolites $S$-adenosyl-methionine and a specific acylated acyl carrier protein, catalyzes the synthesis of the AHL in most bacterial species. The luxR homologs encode a transcription factor that is responsive to the AHL signal. The current paradigm for AHL-mediated gene regulation proposes that an increase in bacterial population size results in accumulation of extracellular AHL (which is in equilibrium with the cell interior) until it reaches a threshold concentration to affect gene expression. Beyond this threshold population size, AHL concentrations increase rapidly, because the transcription of the AHL synthase gene is positively regulated by AHL (autoinduction). Upon AHL binding, the AHL regulator protein undergoes a conformational change resulting in a stable and multimeric form that is able to activate gene expression at a specific promoter consensus sequence known 
as the lux box (Loh et al. 2002; Whitehead et al. 2001). Although, AHL were originally described as regulators of bioluminescence in a few marine Vibrio spp., it is now recognized that many gram-negative plant-associated and phytopathogenic bacteria synthesize and respond to AHL (Cha et al. 1998; Elasri et al. 2001; Gray and Garey 2001; Manefield and Turner 2002).

Many traits in plant-pathogenic and plant-associated bacteria are regulated by quorum sensing signaling (Loh et al. 2002; Von Bodman et al. 2003; Whitehead et al. 2001). For example, the AHL regulator CarR and the AHL signal synthesized by CarI are required for the production of the carbapenem antibiotic and of several exoenzymes involved in the maceration of plant tissues in Erwinia carotovora (Bainton et al. 1992; Jones et al. 1993; McGowan et al. 1995; Pirhonen et al. 1993). The production of the exopolysaccharide virulence factor of Pantoea (Erwinia) stewartii at high cell densities requires AHL and the regulator EsaR (Beck von Bodman and Farrand 1995; Beck von Bodman et al. 1998). The beneficial rhizosphere bacterium $P$. aureofaciens has two separate and nonhiercharchical quorum sensing systems, PhzI/PhzR and CsaI/CsaR (Wood et al. 1997; Wood and Pierson 1996; Zhang and Pierson 2001). Both systems are required for the production of exoproteases and colonization of the wheat rhizosphere. In contrast, the production of phenazine antibiotics is regulated by the $\mathrm{PhzI} / \mathrm{PhzR}$ system, while the expression of cell surface properties is under the control of the CsaI/CsaR system (Zhang and Pierson 2001). Thus, quorum sensing apparently plays a major role in the interaction between plant and microbes.

Given that the survival of $P$. syringae B728a on leaves exhibits cell-density dependence (Monier and Lindow 2003, 2004), we investigated the process of cell-cell signaling via AHL in this species to better identify factors that contribute to epiphytic fitness. AHL production has been described in various strains of P. syringae pv. syringae (Cha et al. 1998; Dumenyo et al. 1998; Elasri et al. 2001; Kinscherf and Willis 1999; Kitten et al. 1998); however, little is known of the genetic determinants required for the production of this signal or its regulation in this species. The gene encoding an AHL synthase, ahlI, has been characterized in $P$. syringae pv. syringae, and its inactivation abolished AHL production (Dumenyo et al. 1998; Kinscherf and Willis 1999). It has also been shown that the GacS/GacA

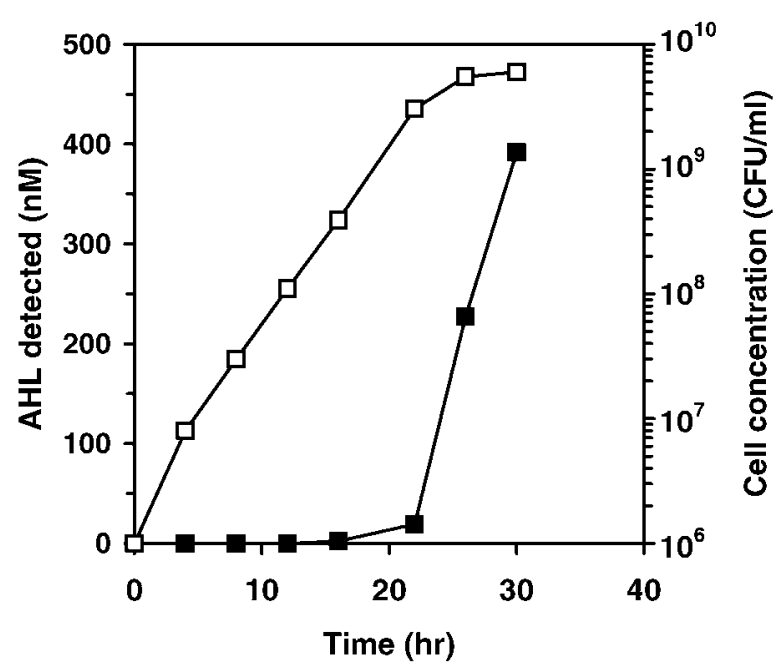

Fig. 1. $N$-acyl-homoserine lactone (AHL) production in Pseudomonas syringae B728a. The cell concentration of culture (open squares) and AHL concentration in culture supernatants (closed squares) were measured at different times during cell growth. The results of a single experiment representative of several separate experiments are shown. two-component system activates AHL production (Kitten et al. 1998) and transcription of ahlI (Dumenyo et al. 1998); however, other regulators of AHL production are not known. We report here a role of AHL-dependent communication among cells of $P$. syringae B728a on epiphytic fitness and a detailed analysis of the quorum sensing system. We also provide evidence for a novel regulator of AHL production and epiphytic fitness and propose a model for density-dependent gene expression in this strain.

\section{RESULTS}

\section{Identification of LuxI-LuxR homologs in $P$. syringae pv. syringae $\mathrm{B} 728 \mathrm{a}$.}

While the dominant AHL of $P$. syringae pv. syringae B728 was reported to be 3-oxo-hexanoyl-homoserine lactone (3oxo-C6-HSL) (Cha et al. 1998), the pattern and abundance of its production was unknown. To further characterize the production of AHL in this strain, cultures were grown to various cell concentrations, and the AHL abundance was quantified by a bioassay with Agrobacterium tumefaciens harboring a tra::lacZ gene fusion (Piper et al. 1993) (Fig. 1). AHL (1 to 10 $\mathrm{nM}$ ) was first detected in cultures with cell concentrations as low as $2 \times 10^{8} \mathrm{CFU} / \mathrm{ml}$. AHL concentrations increased rapidly with further increases in cell concentration, when maximal AHL concentrations ( $>400 \mathrm{nM})$ were observed at cell densities over $10^{9} \mathrm{CFU} / \mathrm{ml}$. The synthesis of AHL in strain B728a occurs in a cell density-dependent manner and in concentrations similar to other gram-negative bacteria (de Kievit and Iglewski 2000; Loh et al. 2002; Miller and Bassler 2001; Pierson et al. 1999; Whitehead et al. 2001), including P. syringae pv. syringae B3A (Dumenyo et al. 1998).

To better understand the mechanism of cell density-dependent production of AHL in P. syringae $\mathrm{B} 728 \mathrm{a}$, the genes required for its production were cloned and characterized. The gene encoding a putative AHL synthase was isolated from strain B728a by polymerase chain reaction (PCR) using sequence-specific primers from a small portion of a homolog of the ahlI gene from $P$. syringae B3A. This PCR-amplified fragment was used as a hybridization probe to screen a cosmid library of strain B728a. One cosmid (6-11) contained a gene with $99 \%$ sequence identity to the ahlI gene from $P$. syringae pv. syringae B3A (Dumenyo et al. 1998). The ahlI gene isolated from strain B728a encodes a predicted 226-amino acid AHL synthase protein that was 85 and $76 \%$ identical to PsyI from $P$. syringae pv. tabaci and PsmI from $P$. syringae pv. maculicola, respectively. Analysis of the ahlI promoter region revealed a 20-nt lux box consensus sequence that was centered 62.5 bp upstream from the putative transcription start site (Fig. 2A). Multiple sequence alignment demonstrated that the lux box in ahlI was closely related to those in psmI from $P$. syringae pv. maculicola (Elasri et al. 2001), esaI from Pantoea stewartii (Beck von Bodman and Farrand 1995), and luxI from Vibrio fischeri (Devine et al. 1989) (Fig. 2B). The presence of this regulatory element suggests that ahlI is subject to activation by a regulator of the LuxR family. As expected, a gene adjacent to $a h l l$, termed $a h l R$, was identified that encoded a predicted 247-amino acid protein having $89 \%$ sequence identity with the AHL regulators PsmR and PsyR from $P$. syringae pv. maculicola and $P$. syringae pv. tabaci, respectively, and $33 \%$ sequence similarity to EsaR from Pantoea stewartii. Analysis of putative conserved protein domains revealed that AhlR contains an autoinducer-binding domain near its amino terminus (amino acids 25 to 171) and a DNA-binding domain with a helix-turn-helix motif characteristic of the LuxR family close to its carboxyl terminus (amino acids 187 to 241). The $a h l I$ and $a h l R$ genes are transcribed convergently (Fig. 2A). 
Such an orientation for the genes encoding the AHL synthase and the AHL regulator has been reported for other phytopathogenic and plant-associated bacteria (Elasri et al. 2001; Gray and Garey 2001), with the exception that in $P$. syringae pv. syringae, the $3^{\prime}$ ends of the ahlI and $a h l R$ genes do not overlap (Fig. 2A). An open reading frame (ORF) with sequence similarity to an aromatic aminotransferase (ORF1) was located upstream of the putative translation start site for ahlI (Fig. 2A). Other ORFs that were upstream of $a h l R$ showed sequence similarity to a pyruvate dehydrogenase E1 component (ORF2) and transketolase (ORF3). No lux box consensus sequence was found in the promoter-proximal region of these ORFs, suggesting that they are not regulated in a cell density-dependent manner.

\section{Isolation of a novel regulator of $\mathrm{AHL}$ production and epiphytic fitness in $P$. syringae $\mathrm{B} 728 \mathrm{a}$.}

To identify other genes that modulate AHL production, $P$. syringae $\mathrm{B} 728 \mathrm{a}$ was subjected to random transposon mutagenesis. While 11 of the 2,000 transposon mutants that were tested exhibited lower AHL production than the parental strain, mutant 538 exhibited the greatest reduction in AHL production. Southern blot analysis demonstrated that this mutant contained only a single copy of the transposon (data not shown). To determine the gene disrupted in mutant 538, the region flanking the transposon insertion site was cloned, sequenced, and found to contain a 615-bp ORF. Taking advantage of the biased codon usage in bacteria such as $P$. syringae with high $\mathrm{G}+\mathrm{C}$ content in their genomes, nucleotide sequence analysis revealed a high $\mathrm{G}+\mathrm{C}$ content at the third base of each codon throughout the entire ORF, supporting its assignment as a functional gene. BLAST sequence analysis revealed that this ORF encodes a putative transcriptional activator of 204 amino acids with a helix-turn-helix motif near its amino terminus (amino acid residues 15 to 61), typical of the TetR family of DNA-binding proteins (Hillen and Berens 1994). The pre- dicted product of this gene had significant sequence identity to that of genes encoding putative transcription regulators from $P$. syringae pv. tomato DC3000 (90\%), P. fluorescens Pf-5 (58\%), and Xanthomonas campestris pv. campestris ATCC33913 (55\%). This gene product also had low sequence identity $(28 \%)$ with a putative regulator encoded by the PA3678 gene from $P$. aeruginosa PA01, a gene that is controlled in a density-dependent manner (Schuster et al. 2003). These sequence similarities suggest that a transcriptional regulator of traits involved in density-dependent gene expression was impaired in mutant 538.

To examine the importance of AHL production in the epiphytic fitness of bacteria, the mutants impaired in AHL production and the parental strain were spray-inoculated on bean leaves, and their epiphytic population sizes compared after exposing plants to successive moist (conducive) and dry (stressful) conditions. P. syringae mutant 538, as well as an ahlI $I^{-}$ahlR ${ }^{-}$double mutant, $P$. syringae A9, were found to be significantly impaired in their ability to survive the stresses of desiccation on leaves (Fig. 3). Although all strains grew at a similar rate and to similar population sizes under moist conditions, the population size of mutant 538 was sevenfold lower than the wild-type strain when examined two days after exposure to desiccation stress. The $a h l I^{-} a h l R^{-}$double mutant was similarly impaired in its ability to survive dry conditions on bean leaves (Fig. 3). Mutant 538 typically was less fit than the $a h l I^{-} a h l R^{-}$double mutant when assayed for stress survival after only a day or two on bean leaves in all experiments. Since the gene inactivated in mutant 538 is apparently a regulatory gene involved in both AHL production and in stress survival on leaves, it was designated as aefR for AHL and epiphytic fitness regulator.

The role of AefR as a putative regulator of AHL production was further defined by quantifying the amount of AHL produced by an $a e f R^{-}$mutant as a function of cell concentration.

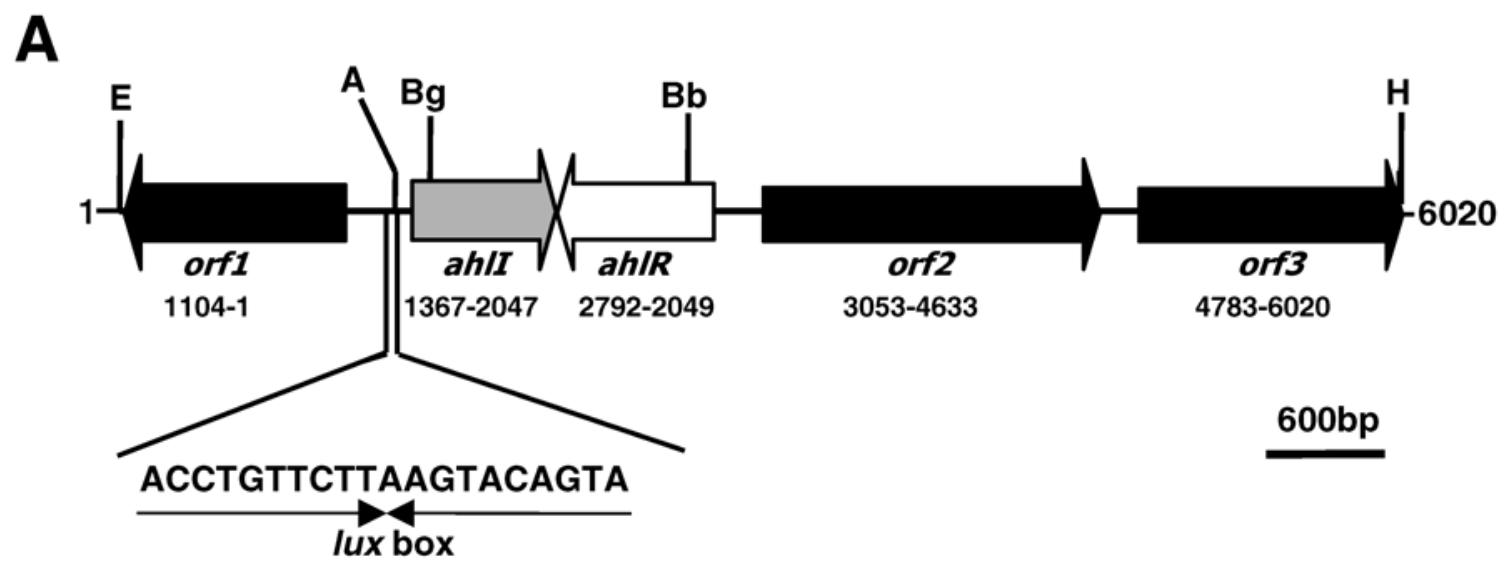

B

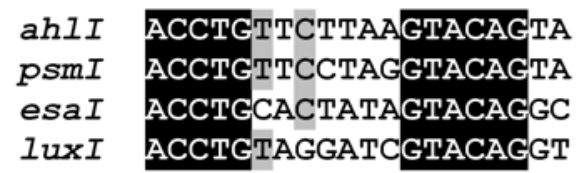

Fig. 2. The $N$-acyl-homoserine lactone (AHL) biosynthesis locus in Pseudomonas syringae B728a. A, Schematic diagram of ahll encoding an AHL synthase and ahlR encoding an AHL regulator. Below, a putative 20-bp lux box sequence with dyad symmetry, as indicated by the convergent arrows, is located upstream of the putative transcription start site of ahlI. The locations of other nearby genes that were identified show sequence similarity to an amino transferase (ORF1), pyruvate dehydrogenase $\mathrm{E} 1$ component $(\mathrm{ORF} 2)$, and a transkeolase $(\mathrm{ORF} 3) . \mathrm{A}=A f l \mathrm{II} ; \mathrm{Bb}=B b s \mathrm{I} ; \mathrm{Bg}=B g l \mathrm{II} ; \mathrm{E}=E c o \mathrm{RI} ;$ and $\mathrm{H}$ = HindIII. B, Multiple sequence alignment of lux boxes identified in the ahlI gene from P. syringae pv. syringae, the psmI gene from $P$. syringae pv. maculicola, the esaI gene from Pantoea stewartii, and the luxI gene from Vibrio fischeri. Identical nucleotides are highlighted in the black and gray boxes. 
The production of AHL was substantially reduced in the aefR mutant when compared with wild-type cells (Fig. 4A). In late $\log$ growth phase cultures in which wild-type cells had initiated the synthesis of AHL, the aefR $R^{-}$mutant produced less than half the AHL of the parental strain. The amount of AHL produced by the aefR $R^{-}$mutant was threefold lower than that of wild-type cells, even during the stationary growth phase when higher levels of AHL were produced by wild-type cells. To confirm that the reduced AHL production in mutant 538 was due to inactivation of $a e f R$ and not due to a secondary mutation elsewhere, the aefR structural gene was expressed in trans in mutant 538 in the stable multicopy plasmid pBQ7. Introduction of aefR restored AHL production in mutant 538 to levels even higher than that in wild-type cells (Fig. 4A), while introduction of promoterless reporter plasmid (pPROBE-OT) alone did not rescue AHL production (Fig. 4A). All strains had similar growth rates, confirming that the reduced AHL production in an aefR ${ }^{-}$mutant was not due to an altered growth of the cells (Fig. 4B). These results suggest that AefR contributes to the accumulation of maximal levels of AHL.

\section{AefR is a regulator of ahlI expression.}

The temporal pattern of ahlI expression and its dependence on AefR was explored in strains harboring a $g f p$ reporter gene fusion to ahlI in trans. The promoter-proximal region of ahlI $\left(\mathrm{P}_{a h l I}\right)$ was fused to a promoterless $g f p$ reporter gene in the stable multicopy plasmid pBQ9, and the transcriptional activity of ahlI was estimated from cell-normalized measurements of green fluorescent protein (GFP) fluorescence. For this analysis, cultures that were used for inoculum were grown only to a low cell concentration $\left(<10^{7} \mathrm{CFU} / \mathrm{ml}\right)$, to avoid the accumulation of AHL and resultant autoinduction of ahlI that occurs at high cell densities. The expression of ahlI as measured by GFP fluorescence in wild-type cells harboring pBQ9 increased dramatically with increasing cell concentration (Fig. 5). While almost no expression of the $\mathrm{P}_{a h l l}:: g f p$ gene fusion was observed in cultures containing less than about $2 \times 10^{8} \mathrm{CFU} / \mathrm{ml}$, and little expression was seen in cultures at about $1 \times 10^{9} \mathrm{CFU} / \mathrm{ml}$. Expression suddenly

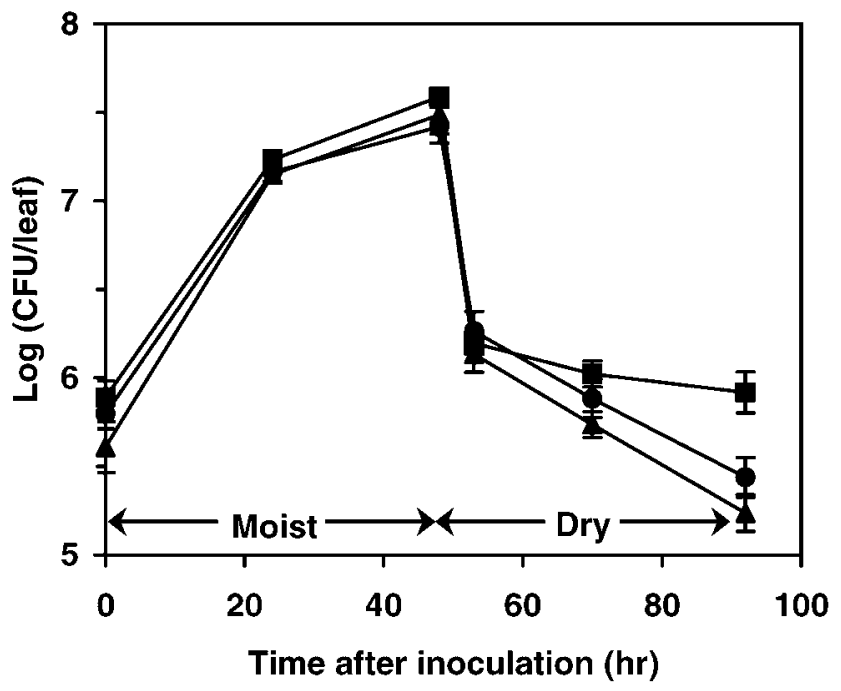

Fig. 3. Growth and survival on bean leaves of Pseudomonas syringae strains differing in $\mathrm{N}$-acyl-homoserine lactone production. The population

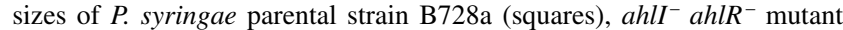
strain A9 (circles), and $a e f R^{-}$mutant strain 538 (triangles) on bean leaves that were first incubated for $48 \mathrm{~h}$ under moist conditions followed by exposure to dry conditions for $48 \mathrm{~h}$ are shown. The vertical bars represent the standard error from the determination of a $\log _{10}$-transformed bacterial populations. increased in cultures having more than $5 \times 10^{9} \mathrm{CFU} / \mathrm{ml}$ (Fig. 5). The ahlI expression levels correlated well with the AHL production at a given cell concentration (Fig. 1). In agreement with previous findings (Dumenyo et al. 1998), the expression of ahlI was dramatically reduced in the $g a c A^{-}$ mutant $P$. syringae BGACX (Fig. 5). Similarly, the aefR mutant had a severely impaired ahlI expression; virtually no expression was observed in cultures before the stationary phase, and only slight expression was observed at later stages of growth (Fig. 5). Both the $g a c A^{-}$and $a e f R^{-}$mutant strains had growth rates similar to wild-type cells, indicating that the reduced ahlI expression was not an indirect effect due to reduced growth (data not shown). As expected, no expression
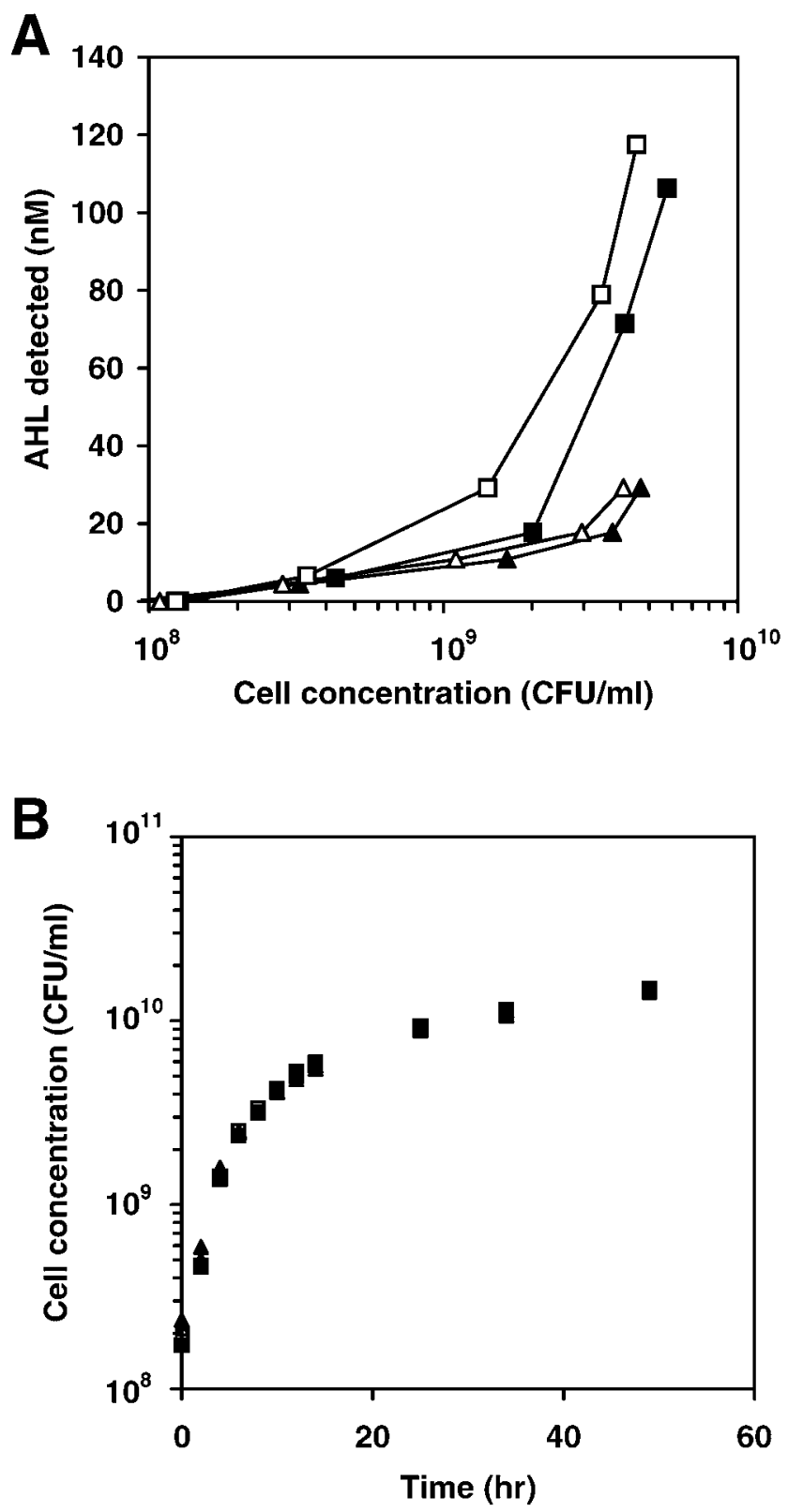

Fig. 4. $N$-acyl-homoserine lactone (AHL) production in Pseudomonas syringae strains differing in the expression of aefR. A, The production of AHL is shown in cultures of $P$. syringae parental strain B728a (closed squares) and the aefR- mutant strains 538 (closed triangles), 538(pBQ7) (open squares), and 538(pProbe-OT) (open triangles) grown to different cell concentrations. The results of a single experiment that is representative of four separate experiments are shown. B, Population sizes of the $P$. syringae strains described in A at different times after inoculation. 
of ahlI was observed in an $a h l I^{-} a h l R^{-}$double mutant harboring pBQ9 (data not shown). The cell-normalized fluorescence of the $\mathrm{P}_{a h l l}: \because g f p$ fusion in an $a h l I^{-} a h l R^{-}$double mutant was similar to background fluorescence levels obtained in wild-type cells harboring the promoterless reporter plasmid pPROBE-OT (approximately 100 fluorescence units) (data not shown).

To confirm that ahlI expression was dependent on AefR, an intact copy of aefR was supplied in trans in the multicopy plasmid $\mathrm{pBQ} 13$. The aefR ${ }^{-}$mutant of $P$. syringae harboring pBQ13 expressed ahlI at a higher level than in an aefR mutant and a sixfold higher level than the wild type, indicating complementation of the mutant phenotype (Fig. 5). Furthermore, provision of additional copies of aefR in wild-type cells resulted in a particularly pronounced increase in ahlI expression during late log and early stationary phases, when little expression was observed in wild-type cells. In contrast, expression of the $\mathrm{P}_{a h l l}: \because g f p$ fusion was not enhanced by supplying aefR in trans in the $g a c A^{-}$mutant $P$. syringae BGACX (Fig. 5), indicating that an overexpression of aefR cannot complement a $g a c A^{-}$mutation. As expected, the cell-normalized GFP fluorescence of an $a h l I^{-} a h l R^{-}$mutant harboring pBQ13 was similar to that of wild-type cells harboring pProbe-OT (data not shown).

To further dissect the role of AefR and GacA on the AhlIAhlR quorum sensing system, the effect of exogenous addition of synthetic AHL to $P$. syringae strains harboring a $\mathrm{P}_{a h l l}: \because g f p$ fusion was measured. Addition of $10 \mu \mathrm{M}$ of 3 -oxoC6-HSL to an aef $R^{-}$mutant of $P$. syringae restored the expression of ahlI to a level above that observed in wild-type cells without exogenous AHL added (Fig. 6). The expression of ahlI was also completely restored when exogenous AHL was added to cultures of the $g a c A^{-}$mutant (Fig. 6). Furthermore, ahlI expression increased when AHL was added to wild-type $P$. syringae cells, particularly at low cell concentrations (Fig. 6). These observations in wild-type cells indicated that ahlI expression was responsive to AHL, as expected of a

\section{Cell concentration (Log CFU/ml)}

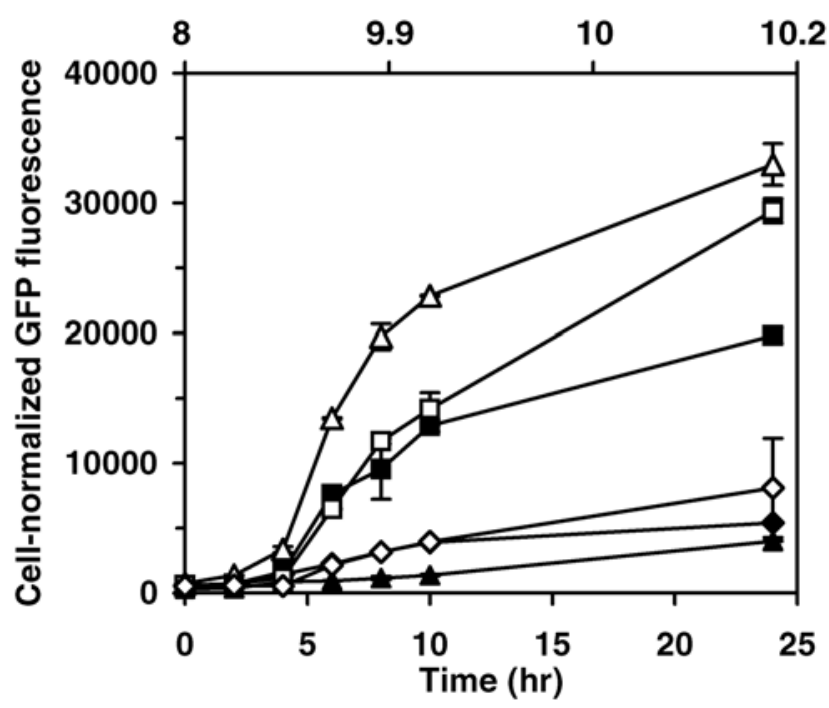

Fig. 5. Complementation of ahlI expression by supplying aefR in trans. The expression of ahlI was examined at various times by measuring green fluorescent protein (GFP) fluorescence of cultures of Pseudomonas syringae parental strain B728a (squares), gacA $A^{-}$mutant strain BGACX (diamonds), and aefR ${ }^{-}$mutant strain 538 (triangles) harboring either pBQ9 (closed symbols) or pBQ13 (open symbols). The vertical bars represent the standard deviation of mean estimates of cell-normalized GFP fluorescence. positive feedback mechanism typical of other quorum sensing systems. These results have also provided additional evidence that AefR and GacA have a role in regulating ahlI expression. The exogenous addition of AHL restored the deficient expression of ahlI that was observed in either an $a e f R^{-}$or $g a c A^{-}$mutant by providing relevant concentrations of AHL for AhlR to activate the ahlI promoter. These observations also suggest that the expression of $a h l R$ is also unaffected in either an $a e f R^{-}$or $g a c A^{-}$mutant. To further confirm this hypothesis, the expression of $a h l R$ was examined in these mutants harboring a $\mathrm{P}_{a h l R}: \because g f p$ reporter gene fusion in the plasmid pAhlR3. The expression of $a h l R$ was similar in both $a e f R^{-}$and $g a c A^{-}$mutants when compared with wild-type cells (data not shown).

Given the role of GacA as an important regulator for production of AHL in $P$. syringae (Dumenyo et al. 1998; Kinscherf and Willis 1999; Kitten et al. 1998), the question emerged as to whether aefR was a downstream gene in a pathway regulated by GacA. To determine whether the GacS/GacA regulon had an effect in the expression of aefR, fluorescence was measured in $P$. syringae BGACX harboring pBQ6 in which the promoter-proximal region of aefR $\left(\mathrm{P}_{\text {aefR }}\right)$ was fused to a promoterless $g f p$ reporter gene. The expression of $a e f R$ in $P$. syringae BGACX was about twice that in wild-type cells at all phases of growth (Fig. 7). Similar results were obtained when the transcriptional activity of the $\mathrm{P}_{a e f R}:: g f p$ fusion was examined in a gacS $S^{-}$mutant, $P$. syringae NPS3136 (Fig. 7). In contrast, the expression of a gacA::gfp fusion was similar in an $a e f R^{-}$mutant and the parental strain (data not shown). Furthermore, the expression of the $\mathrm{P}_{a e f R}:: g f p$ fusion was also higher in an aefR $R^{-}$mutant when compared with wild-type cells (Fig. 7). Thus, these results demonstrate that the expression of aefR is not dependent on the two component regulatory proteins GacA or GacS.

\section{Cell concentration (Log CFU/ml)}

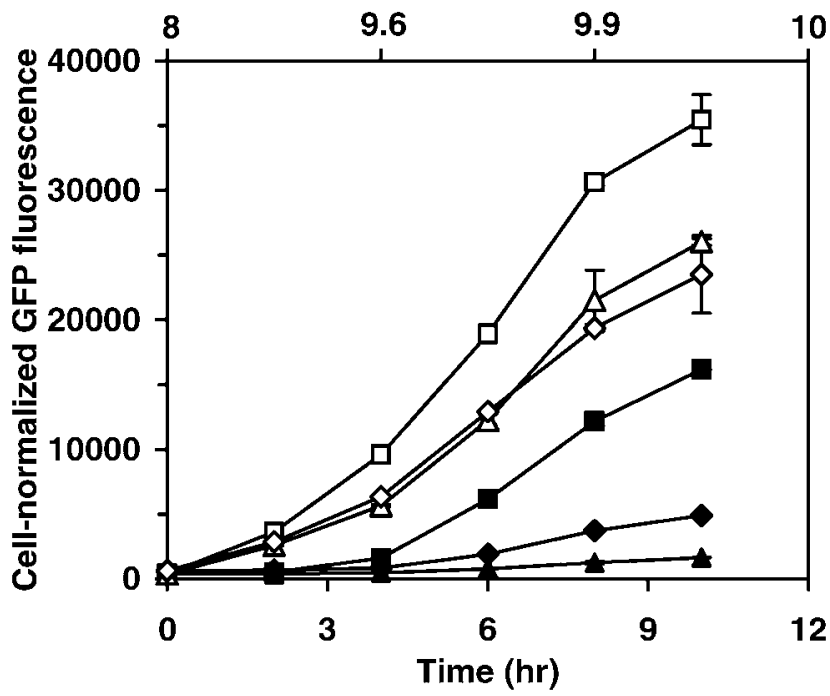

Fig. 6. Effects of exogenous $N$-acyl-homoserine lactone on ahlI expression in Pseudomonas syringae strains with disrupted AefR and $\mathrm{GacA}$ regulators. The expression of $a h l I$ was examined at various times by measuring green fluorescent protein (GFP) fluorescence of cultures of $P$. syringae parental strain B728a (squares), aefR $R^{-}$mutant strain 538 (triangles), and $\mathrm{gacA}^{-}$mutant strain BGACX (diamonds) harboring pBQ9 in the presence (open symbols) or absence (closed symbols) of $10 \mu \mathrm{M}$ synthetic 3-oxo-hexanoyl-homoserine lactone. The vertical bars represent the standard deviation from the mean of estimates of cell-normalized GFP fluorescence. 


\section{DISCUSSION}

The occurrence of $P$. syringe pv. syringae in large cellular aggregates that are more tolerant of stresses than more solitary cells on leaves has suggested that cell density-dependent processes are responsible for some of its epiphytic fitness (Monier and Lindow 2003). This observation stimulated our interest in exploring the mechanisms by which cell density-dependent traits could be expressed in this plant-pathogenic bacterium. Support for the hypothesis that AHL-dependent traits play an important role in the epiphytic fitness of $P$. syringae was provided by the observation that mutants in two separate genes required for AHL production were reduced in their ability to tolerate desiccation stress on leaves (Fig. 3). Interestingly, such mutants exhibited normal growth rates and achieved similar population sizes as the wild-type strain on leaves that were kept in humid conditions (Fig. 3), similar to other epiphytic fitness mutants (Beattie and Lindow 1994). While many bacteria appear to be able to grow on leaves under "conducive conditions" (O'Brien and Lindow 1989), apparently only epiphytes with special adaptations are capable of surviving the stressful conditions that typify leaves at other times. More work will be required to determine those genes in $P$. syringae that are expressed in a cell density-dependent manner, presumably under control of the AhlI-AhlR quorum sensing system described here, that also contribute to epiphytic fitness. Many genes are under quorum sensing control in $P$. aeruginosa (Schuster et al. 2003; Wagner et al. 2003; Whiteley et al. 1999). It is tempting to speculate that a variety of stressresponse genes, under the control of $r p o S$, which itself is linked to quorum sensing systems in species such as $P$. aeruginosa (Latifi et al. 1996; Whiteley et al. 2000), may play a role in the epiphytic fitness of $P$. syringae. Further work will also be required to determine the size of aggregates of $P$. syringae on leaves in which autoinduction of the AhlI-AhlR system is operative. Given that cells of $P$. syringae in aggregates larger

\section{Cell concentration (Log CFU/ml)}

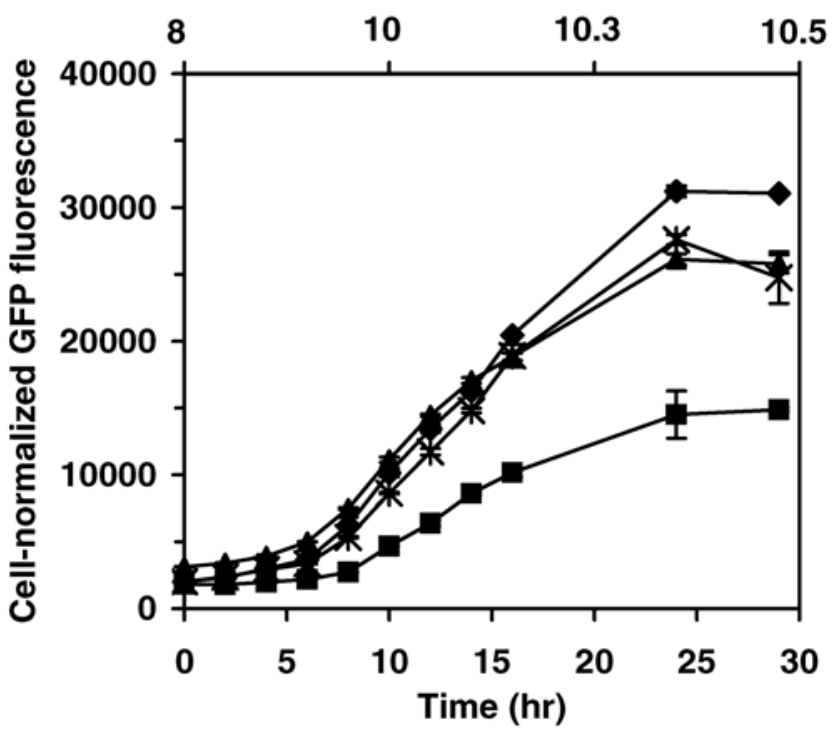

Fig. 7. Transcriptional activity of aefR in $\mathrm{gacA}^{-}$and $\mathrm{gacS}^{-}$mutants of Pseudomonas syringae. The expression of aefR was examined at various times by measuring the cell-normalized green fluorescent protein (GFP) fluorescence from cultures of $P$. syringae parental strain B728a (squares), aefR $R^{-}$mutant strain 538 (triangles), gac $S^{-}$mutant strain NPS3136 (asterisks), and $g a c A^{-}$mutant strain BGACX (diamonds) harboring pBQ6. The vertical bars represent the standard deviation of estimates of cell-normalized GFP fluorescence. than about 100 cells are more tolerant of stress on leaves than more solitary cells (Monier and Lindow 2003), we might expect that autoinduction might be possible in such relatively small aggregates if conditions on the leaf allowed accumulation of the AHL signal produced by this species.

The AhlI-AhlR quorum sensing system in $P$. syringae has many similarities to that described in other gram-negative bacteria. The production of 3-oxo-C6-HSL in P. syringae clearly occurs in a cell-density dependent manner (Fig. 1). Only as cells grown in liquid culture entered the late exponential growth phase were even low levels of the signal detected. However, once the population reached a cell concentration above about $10^{9} \mathrm{CFU} / \mathrm{ml}$, the production of the AHL signal increased dramatically with further cell multiplication (Fig. 1). Synthesis of AHL was preceded by an increase in the transcriptional activity of ahlI, encoding an AHL synthase. ahlI is expressed at low basal levels during the early logarithmic growth phase, and the expression increased as cultures reached higher cell densities. Furthermore, this system results in a positive feedback of AHL on the expression of ahll; addition of exogenous AHL increased ahlI expression (Fig. 6). In contrast to $a h l I, a h l R$ was expressed constitutively at all cell concentrations and at levels lower than the induced levels of ahlI. These findings differ from those described for another AHL regulator, LasR from $P$. aeruginosa, whose expression is apparently cell-density dependent (Albus et al. 1997).

Recent evidence has demonstrated that quorum sensing is subject to modulation by additional regulatory proteins (Fuqua et al. 2001; Pearson 2002). These regulatory proteins exert their influence by distinct mechanisms. While the expression of the AHL synthase or the AHL regulator is often controlled at the transcriptional level, regulation can also occur at the post-transcriptional level whereby the stability of the mRNA transcript or the activity of the protein is altered. The distinct regulatory mechanisms that either activate or repress quorum sensing ensure the proper timing of the density-dependent gene expression to be coupled to the growth phase and physiological state of the cell (Fuqua et al. 2001; Pearson 2002).

AefR is an important and novel regulator of autoinduction in $P$. syringae. Analysis of the AefR amino acid sequence demonstrated the presence of a helix-turn-helix motif that is highly similar to that found in transcriptional factors of the TetR family. AefR was required for maximal levels of AHL production in strain B728a and, consequently, for transcription of ahlI. How does AefR exert its regulatory role on AHL production? One possible way would be to positively activate quorum sensing by participating in a direct interaction with sequences upstream of $a h l I$ and $a h l R$. Such a type of regulatory mechanism has been described for Vfr, a positive regulator of LasR in $P$. aeruginosa (Albus et al. 1997). However, such a mechanism is unlikely for AefR because addition of exogenous AHL completely restored the expression of $a h l I$ in an aefR ${ }^{-}$mutant (Fig. $6)$. The fact that the defect in ahlI expression in the aefR ${ }^{-}$ mutant is relieved by addition of the product of the AhlI synthase suggests that AefR may not be absolutely required for ahlI transcription by a direct interaction with the promoter sequence. AefR probably plays a more indirect role in ahlI transcription since the deficiency in AHL production in the aef $R^{-}$mutant can be overcome by excess of exogenous AHL. Alternatively, AefR could act at the post-transcriptional level, for example, by regulating the stability of mRNA or protein as previously demonstrated for other regulators of quorum sensing (Chatterjee et al. 2002; Chugani et al. 2001; de Kievit et al. 1999; Ledgham et al. 2003; Pessi et al. 2001; Zhu and Winans 2001); however, these post-transcriptional mechanisms regulate quorum sensing in a negative fashion. Another simple model to explain AefR mode of action in P. syringae would 
have it controlling the availability of precursors required for the production of AHL (Fig. 8). The large but incomplete reduction in AHL production and ahlI expression in an aefR mutant (Figs. 4 and 5) might be explained if AefR control of precursor production is not tight. It would also allow for an overexpression of ahlI in an aefR ${ }^{-}$mutant when large amounts of exogenous AHL were supplied (Fig. 6).

While AefR regulates quorum sensing, its own transcription appears independent of AHL concentration. Addition of exogenous 3-oxo-C6-HSL did not affect the expression of aefR at various cell densities when compared with the expression levels of this gene fusion in the absence of AHL (data not shown). Furthermore, the temporal expression of the aefR, like that of $a h l R$, was similar at various cell concentrations in wild-type cells. The fact that these regulators are not expressed in a celldensity dependent manner suggests that additional factors may modulate the proper timing of their regulatory properties on the expression of ahlI. Evidence for this hypothesis is provided from the experiment described in Figure 6 in which the addition of exogenous AHL resulted in an enhanced but not advanced ahlI expression in wild-type cells. It is possible that a regulator, such as MvaT (Diggle et al. 2002), which ensures the proper timing of quorum sensing in $P$. aeruginosa, may operate in $P$. syringae.

The GacS/GacA two-component regulatory system plays a pivotal role in the synthesis of AHL, in addition to the production of other secondary metabolites such as hydrogen cyanide and antibiotics in various strains of pseudomonads (Chancey et al. 1999; Dumenyo et al. 1998; Kitten et al. 1998; Laville et al. 1992; Reimmann et al. 1997). In P. syringae pv. syringae, GacA regulates the production of the phytotoxin syringomycin, protease production, and lesion formation on bean leaves (Hrabak and Willis 1993; Kitten et al. 1998; Rich et al. 1994). GacA is also required for maximal levels of AHL production in $P$. syringae (Kitten et al. 1998), via a different pathway from the one involved in the regulation of these other phenotypes (Kinscherf and Willis 1999; Kitten et al. 1998). This positive effect in AHL production is achieved by activating the transcription of ahlI (Dumenyo et al. 1998). A similar observation was obtained in another $P$. aureofaciens where GacA is also required for the transcription of the AHL synthase gene phzI (Chancey et al. 1999). However in P. syringae, both GacA and AefR have a role in regulating ahlI expression, possibly by independent pathways since either mutation can be overcome when AHL was supplied exogenously (Fig. 6).

Similar to GacA, AefR is also required for maximal production of AHL and controls the transcription of ahlI. Since both $g a c A^{-}$and $a e f R^{-}$mutants have reduced ahlI expression, the question that emerges is whether aefR is a downstream target of GacA regulation. To explore this possibility, the expression of aefR was examined in both $g a c A^{-}$and $g a c S^{-}$mutants. The expression of aefR was clearly not impaired in either a $g a c A^{-}$ or gacS $^{-}$mutant, suggesting that AefR modulates quorum sensing via a pathway independent of GacA. An additional interesting observation made in this analysis was that aefR expression was higher in both gacA $^{-}$and gacS $^{-}$mutants when compared with wild-type cells grown to high cell densities (Fig.7). In contrast, the expression of gacA was similar in an aef $R^{-}$mutant and wild-type strain at all growth stages. Based on these observations, we hypothesize that the GacS/GacA regulatory pathway downregulates the expression of aefR in $P$. syringae, to achieve a reduction in the extent of activation of ahlI that would otherwise occur at high cell concentrations when AHL concentrations increase (Fig. 8).

Besides being required for maximal AHL production, AefR plays an important role in the epiphytic fitness of $P$. syringae suggesting that AefR may be part of a complex regulatory cas- cade that governs other phenotypes. The epiphytic fitness of an aefR ${ }^{-}$mutant was usually less than that of an $a h l I^{-} a h l R^{-}$mutant when examined 2 to 3 days after inoculation on plants (Fig. 3). Thus, AefR may regulate genes involved in epiphytic fitness independently of AhlR. Given that AefR is expressed even at relatively low cell densities in culture, one possibility is that AefR would be particularly important for the expression of certain genes contributing to fitness during the initial stages of colonization. Further work will focus on the relative epiphytic fitness differences of $a e f R^{-}$and $a h l I^{-} a h l R^{-}$mutants at various times on plants. In addition, the identification of traits regulated by these genes should provide insight into the strategies for epiphytic growth and survival as well as virulence of $P$. syringae on plants.

\section{MATERIALS AND METHODS}

\section{Bacterial strains and growth conditions.}

The bacterial strains and plasmids that were used in this study are described in Table 1 . The source and characteristics of epiphytic $P$. syringae pv. syringae $\mathrm{B} 728 \mathrm{a}$, a pathogen of bean, have been previously described (Loper and Lindow 1987). P. syringae strains were grown in King's B broth (KBB) or solidified medium (KB) (King et al. 1954) at $28^{\circ} \mathrm{C}$. Escherichia coli strains were grown in Luria-Bertani medium (Sambrook et al. 1989) at $37^{\circ} \mathrm{C}$. Agrobacterium tumefaciens NT1(pSVB33, pJM749) indicator strain (Piper et al. 1993) was grown in Luria-Bertani medium or in M9 minimal medium (Sambrook et al. 1989) at $28^{\circ} \mathrm{C}$. The following concentrations of antibiotics were used: ampicillin, $100 \mu \mathrm{g} / \mathrm{ml}$; carbenicillin, $100 \mu \mathrm{g} / \mathrm{ml}$; kanamycin, $50 \mu \mathrm{g} / \mathrm{ml}$; rifampicin, 100 $\mu \mathrm{g} / \mathrm{ml}$; spectinomycin, $20 \mu \mathrm{g} / \mathrm{ml}$; tetracycline, $15 \mu \mathrm{g} / \mathrm{ml}$.

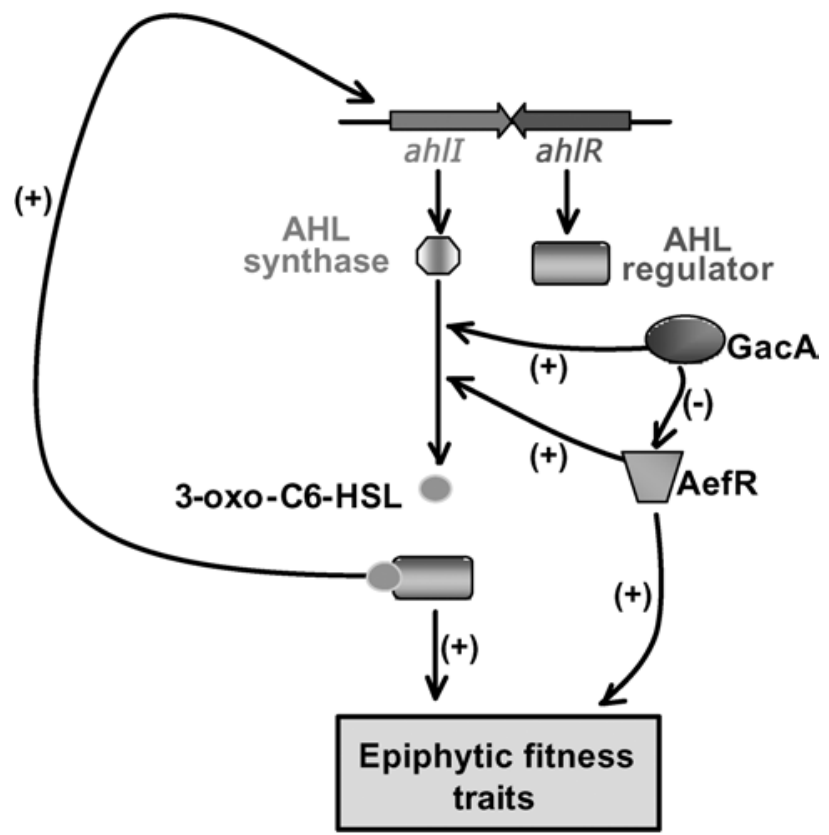

Fig. 8. Model of cell density-dependent regulation in Pseudomonas syringae. The synthesis of the $N$-acyl-homoserine lactone (AHL), 3-oxohexanoyl-homoserine lactone (3-oxo-C6-HSL), requires the expression of the AHL synthase gene, ahlI, and the AHL regulator gene ahlR. The AHL regulator forms a stable complex with 3-oxo-C6-HSL and activates the transcription of ahlI via a typical positive feedback (autoinduction) in which AHL concentrations are produced as cell concentration increases. The regulatory proteins GacA and AefR act independently as activators of the autoinduction process and are required for maximal levels of AHL production by acting downstream of ahlI transcription. At high cell concentrations, GacA and GacS may downregulate the expression of aefR to achieve a reduction in ahlI activation. 


\section{DNA manipulations.}

Isolation of plasmid DNA from $E$. coli, restriction enzyme digestion, DNA subcloning and transformations, and Southern blot hybridizations were performed according to standard procedures (Ausubel et al. 1995; Sambrook et al. 1989) or as recommended by the manufacturer. All plasmids were introduced into $P$. syringae strains by electroporation (Gene Pulser System, Bio-Rad Laboratories, Hercules, CA, U.S.A.) using 2,000 volts, $200 \mathrm{ohms}$, and 25 faradays. DNA primers were synthetized by either Gibco BRL Life Technologies (Rockville, MD, U.S.A.) or Invitrogen (Carlsbad, CA, U.S.A.). DNA sequencing was performed either at the University of CaliforniaBerkeley Sequencing Facility or at Elim Pharmaceuticals (Fremont, CA, U.S.A.). The analysis of nucleotide sequences was performed by using BLAST software. Putative ORFs were predicted with the FramePlot software that examines the randomness of codon usage at the third position of each codon.

\section{Cloning of the luxI-luxR homologs}

from $P$. syringae pv. syringae $\mathrm{B} 728 \mathrm{a}$.

A genomic cosmid library of $P$. syringae B728a was constructed in pLAFR3, as previously described (Andersen et al. 1998). The cosmid library was subjected to colony blot hybridization using a PCR-amplified fragment expected to contain a portion of the luxI homolog to identify cosmid 6-11. PCR amplification with primers 5' CGGATCGGCTTGAATGG 3' and 5' AGAACCGGCTCGACTCC 3', which were derived from a conserved region of the $a h l I_{P s s}$ gene from $P$. syringae
B3A, resulted in a 225-bp fragment that was used as a probe in the hybridization. The location of luxI and luxR homologs in cosmid 6-11 was determined by digesting it with various restriction endonucleases and probing it with the PCR fragment by Southern hybridization, using dioxigenin-dUTP as labeling method (Boehringer Mannheim Biochemicals, Indianapolis, IN, U.S.A.). The luxI and luxR homologs, confirmed by sequence analysis, were cloned in pBluescript as a $6.0-\mathrm{kb}$ EcoRI-HindIII fragment to yield pCPB2.

\section{Construction of $P$. syringae mutant strains.}

Both the ahlI and ahlR genes in P. syringae B728a were disrupted by replacing a $1.5-\mathrm{kb} A f l \mathrm{II}-B b s \mathrm{I}$ fragment internal to ahlI and ahlR from pCPB2 with the 1.3-kb kanamycin gene from Streptococcus faecalis (Trieu-Cuot and Courvalin 1983), resulting in plasmid pCPB39. The EcoRI-HindIII fragment from pCPB39 was then introduced into pLAFR3, yielding pCPB44. Cells of strain B728a harboring pCPB44 were grown for about 50 generations in $\mathrm{KBB}$ amended with rifampicin and then were plated on $\mathrm{KB}$ containing rifampicin and kanamycin to select for allelic exchange recombinants. Tetracycline-sensitive strains, such as mutant A9, were found to have lost pCPB44, due to segregational instability. Isolation of $P$. syringae mutant 538 was achieved by $\operatorname{Tn} 5$ transposition mutagenesis according to previously described procedures (Lindow 1993), with the exception that the plasmid pRL1062a (Cohen et al. 1998) was used. A total of 2,000 transposon mutants were scored individually for AHL production by growing the tested colonies on M9 minimal

Table 1. Bacterial strains and plasmids used in this study

\begin{tabular}{|c|c|c|}
\hline Strain/plasmid & Relevant characteristics $^{\mathbf{a}}$ & Reference or source \\
\hline \multicolumn{3}{|l|}{ Escherichia coli } \\
\hline DH10B & $\begin{array}{c}\mathrm{F}^{-} \text {mcrA } \Delta(\text { mrr-hsd } \mathrm{RMS}-m c r \mathrm{BC}) ; \phi 80 \text { lac } \mathrm{Z} \Delta \mathrm{M} 15 \Delta \text { lacX74 deo } \mathrm{R} \text { rec } \mathrm{A} 1 \text { end } \mathrm{A} ; 1 \mathrm{ara} \Delta 139 \\
\Delta(\text { ara, leu }) 7697 \text { galU galK } \lambda^{-} \text {rpsL; }\left(\mathrm{Str}^{\mathrm{r}}\right) \text { nup } \mathrm{G} \lambda^{-} \text {ton } \mathrm{A}\end{array}$ & $\begin{array}{l}\text { Invitrogen, Carlsbad, CA, } \\
\text { U.S.A. }\end{array}$ \\
\hline DH5 $\alpha$ & 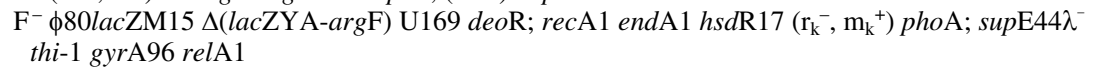 & Invitrogen \\
\hline \multicolumn{3}{|c|}{ Pseudomonas syringae pv. syringae } \\
\hline B728a & $\mathrm{Rf}^{\mathrm{r}}$, wild type, bean pathogen & Loper and Lindow 1987 \\
\hline 538 & $\mathrm{Rf}^{\mathrm{r}} \mathrm{Km}^{\mathrm{r}}, \Delta$ aefR::Tn5, B728a derivative & This study \\
\hline A9 & $\mathrm{Rf}^{\mathrm{r}} \mathrm{Km}^{\mathrm{r}}, \Delta a h l I R:: k m, \mathrm{~B} 728$ a derivative & This study \\
\hline BGACX & $\mathrm{Rf}^{\mathrm{r}} \mathrm{Km}^{\mathrm{r}}, \Delta g a c A:: k m, \mathrm{~B} 728 \mathrm{a}$ derivative & Rich et al. 1994 \\
\hline NPS3136 & $\mathrm{Rf}^{\mathrm{r}} \mathrm{Km}^{\mathrm{r}}, \Delta g a c S:: k m, \mathrm{~B} 728 \mathrm{a}$ derivative & Willis et al. 1990 \\
\hline \multicolumn{3}{|c|}{ Agrobacterium tumefaciens } \\
\hline NTI & Derivative of strain C58 cured of Ti plasmid pTiC58 & Watson et al. 1975 \\
\hline \multicolumn{3}{|c|}{ - } \\
\hline pBluescript II-KS(-) & $\mathrm{Ap}^{\mathrm{r}}$, cloning vector & $\begin{array}{l}\text { Stratagene, La Jolla, CA, } \\
\text { U.S.A. }\end{array}$ \\
\hline pUC18 & $\mathrm{Ap}^{\mathrm{r}}$, cloning vector & Gibco, Rockville, MD, U.S.A. \\
\hline pCR2.1-Topo & $\mathrm{Ap}^{\mathrm{r}} \mathrm{Km}^{\mathrm{r}}$, cloning vector & Invitrogen \\
\hline PPROBE-OT & $\mathrm{Sp}^{\mathrm{r}}$, broad-host-range promoterless $g f p$ expression vector & Miller et al. 2000 \\
\hline PPROBE-TT' & $\mathrm{Tc}^{\mathrm{r}}$, broad-host-range promoterless $g f p$ expression vector & Miller et al. 2000 \\
\hline pRL1062a & $\mathrm{Km}^{\mathrm{r}}$ transposon-bearing plasmid & Cohen et al. 1998 \\
\hline pCPB2 & pBluescript II-KS, containing ahlI and $a h l R$ as a EcoRI-HindIII 6.0-kb fragment & This study \\
\hline pCPB14 & pRL1062a derivative containing a Tn5 insertion in aefR in a $10-\mathrm{kb}$ genomic DNA fragment & This study \\
\hline pCPB16 & pPROBE-TT' containing aefR as a $0.93-\mathrm{kb}$ Bam $\mathrm{H} 1$ fragment & This study \\
\hline pCPB39 & $\mathrm{Ap}^{\mathrm{r}} \mathrm{Km}^{\mathrm{r}}$, pCPB2 containing the ahlIR $: \mathrm{km}$ mutation within a $1.5-\mathrm{kb}$ AflII-BbsI fragment & This study \\
\hline pCPB44 & $\begin{array}{l}\mathrm{Km}^{\mathrm{r}} \mathrm{Tc}^{\mathrm{r}} \text {, pLAFR3 containing the ahlIR: }: \mathrm{km} \text { mutation as a 5.7-kb EcoRI-HindIII fragment } \\
\text { from pCPB39 }\end{array}$ & This study \\
\hline pBQ6 & pPROBE-OT containing the promoter-proximal region of $a e f R$ as a $0.3-\mathrm{kb} X b a \mathrm{I}-S a c \mathrm{I}$ fragment & This study \\
\hline pBQ7 & pPROBE-OT containing aefR as a $1.5-\mathrm{kb}$ SacI-HpaI fragment from pCPB16 & This study \\
\hline pBQ9 & pPROBE-OT containing the promoter-proximal region of $a h l I$ as a $0.35-\mathrm{kb} X b a \mathrm{I}-\mathrm{SacI}$ fragment & This study \\
\hline pBQ13 & pBQ9 containing aefR as a $0.85-\mathrm{kb}$ XbaI fragment & This study \\
\hline pAhlR3 & pPROBE-OT containing the promoter-proximal region of $a h l R$ as a $0.45-\mathrm{kb} X b a \mathrm{I}-S a c \mathrm{I}$ fragment & This study \\
\hline pUCKm & $\begin{array}{l}\mathrm{Km}^{\mathrm{r}} \text {, pUC18 containing the kanamycin resistance gene from Streptococcus faecalis as a XbaI } \\
\text { fragment }\end{array}$ & $\begin{array}{l}\text { This study; Trieu-Cuot and } \\
\text { Courvalin } 1983\end{array}$ \\
\hline pSVB33 & $\mathrm{Km}^{\mathrm{r}}$, containing a 1.8-kb EcoRI fragment encoding traR from pTiC58 & Piper et al. 1993 \\
\hline pJM749 & $\mathrm{Cb}^{\mathrm{r}}$, containing tra: $: l a c Z 749$ reporter fusion & Piper et al. 1993 \\
\hline \multicolumn{3}{|c|}{ - } \\
\hline pLAFR3 & $\mathrm{Tc}^{\mathrm{r}}$, broad-host-range vector incP-1 $r l x_{\mathrm{RK} 2}$ lac $\mathrm{Z} \alpha \cos ^{+}$ & Staskawicz et al. 1987 \\
\hline $6-11$ & $\mathrm{Tc}^{\mathrm{r}}$, pLAFR3 cosmid clone of $P$. syringae B728a chromosomal DNA containing ahlI and ahlR & This study \\
\hline
\end{tabular}

a $\mathrm{Ap}=$ ampicillin; $\mathrm{Cb}=$ carbenicillin; $\mathrm{Km}=$ kanamycin; $\mathrm{Rf}=$ rifampicin; $\mathrm{Sp}=$ spectinomycin; $\mathrm{Tc}=$ tetracycline; $\mathrm{r}=$ resistance 
solidified medium containing $0.5 \%$ glucose for 2 days at $28^{\circ} \mathrm{C}$. This solidified medium was then overlaid with $3 \mathrm{ml}$ of melted $0.75 \%$ agar containing $0.5 \mathrm{ml}$ of an overnight culture of Agrobacterium tumefaciens NT1(pSVB33, JM749) indicator strain and $500 \mu \mathrm{g}$ 5-bromo-4-chloro-3-indolyl $\beta$-D-galactopyranoside (X-Gal) per ml. AHL-deficient mutants were identified with reduced zones of blue coloration surrounding each tested colony. Mutant 538 was further examined by Southern blot hybridization to confirm a single insertion of the transposon.

\section{Cloning of aefR.}

To identify the genomic sequences that were contiguous with the $\operatorname{Tn} 5$ transposon in $P$. syringae mutant 538 , genomic DNA from mutant 538 was digested with ApaI, was selfligated, and was transformed into $E$. coli as described in previous studies (Cohen et al. 1998; Wolk et al. 1991), to generate a clone that was designated pCPB14. DNA sequencing of the $10-\mathrm{kb}$ genomic insert in plasmid pCPB14 was performed by using primers that hybridized to the IS50 region of the transposon to confirm that the single $\mathrm{Tn} 5$ insertion site resided in an ORF that was later designated as $a e f R$. The $a e f R$ gene was first PCR-amplified with the primers 5' TCTGATGTGTCGAGGCCATGG 3' and 5' ACGAAGTGATTCTGCG TGCCCG 3' and then was cloned as a $0.93-\mathrm{kb}$ fragment into the BamHI site of the expression vector pProbe-TT' to create pCPB16. The plasmid pCPB16 was then digested with SacI and $H p a \mathrm{I}$, and the 1.5-kb fragment containing aefR was then cloned into pPROBE-OT to yield pBQ7.

\section{Construction of $g f \boldsymbol{p}$ transcriptional fusion plasmids.}

Transcriptional fusions with the promoter regions of ahlI, $a h l R$, and $a e f R$ with a $g f p$ reported gene were constructed as follows. A $0.35-\mathrm{kb}$ fragment encompassing the promoter region of ahlI was PCR-amplified with the primers 5' TCTA GACTGATCCTGGTGCGTGTGGGCATCGGCCAG 3' and 5' GAATTCATTCTAAAACCCACCCGGCGTCACCAG-CGT 3'. The amplified fragment was first cloned into pCR2.1-Topo (Invitrogen), was excised as an XbaI-SacI fragment, and was further cloned into the multiple cloning site of pProbe-OT, upstream of the promoterless $g f p$ gene, to create pBQ9. The promoter region of $a h l R$ was PCR-amplified as a $0.44-\mathrm{kb}$ fragment with the primers 5'GGGTCTAGACGGGTCTGGGGT GCCAAC 3' and 5' GGGGAGCTCCCAATACGATGCAGAT CG 3 ' and was cloned into pCR2.1-Topo. The promoter region was excised with $X b a I$ and $S a c I$ from pCR2.1-Topo and was cloned into the multiple cloning site of pProbe-OT, to yield pAhlR3. The aefR promoter region was amplified by PCR with the primers 5' GGGTCTAGACTGATGTGTCGAGGCC ATGG 3' and 5' GGGGAGCTCGGAAATGGTTATAGACCG $3^{\prime}$, resulting in a $0.36-\mathrm{kb}$ fragment that was then cloned into XbaI-SacI-digested pPROBE-OT, to yield pBQ6. A 0.85-kb fragment containing the promoter-proximal region and intact aefR gene was PCR-amplified with the primers 5'CGGTCTAG ACTGATGTGTCGAGGCCATGGTTCGCTGACTCCTGG 3' and 5' GGGTCTAGATTGTGCTGGACTGACCGCTTC 3' and cloned into the $X b a \mathrm{I}$ site of pBQ9 to create pBQ13 in which aefR is transcribed divergently from the ahlI promoter.

\section{Quantification of AHL production.}

AHL were extracted with ethyl acetate from the supernatants of 10-ml cultures grown in KBB, as in previous studies (Shaw et al. 1997). Extracts were concentrated to near dryness under vacuum, and residues were resuspended in a final volume of $25 \mu \mathrm{l}$ of high-performance liquid chromatographygrade ethyl acetate. Samples (5 to $25 \mu \mathrm{l}$ ) were then spotted onto $20 \times 20$-cm silica C18 reverse-phase thin-layer chromatography (TLC) plates (200- $\mu$ m layer) (Mallinckrodt Baker,
Inc., Phillipsburg, NJ, U.S.A.) and were allowed to dry. AHL were detected with a bioassay similar to that described by Shaw and associates (1997), with the following modifications: the TLC plates were overlaid with $100 \mathrm{ml}$ of M9 minimal medium containing $5 \mathrm{ml}$ of an overnight culture of Agrobacterium tumefaciens NT1(pSVB33, pJM749) AHL indicator strain (Piper et al. 1993) grown in M9 minimal medium, $0.5 \%$ glucose, $2 \mathrm{mM}$ magnesium sulfate, $100 \mu \mathrm{g} \mathrm{X-Gal} \mathrm{per} \mathrm{ml,} \mathrm{and}$ $0.7 \%$ noble agar that was kept at $40^{\circ} \mathrm{C}$. The medium was mixed thoroughly and was carefully added to the TLC plate to create a uniform top layer of agar that was about 3 to $4 \mathrm{~mm}$ in depth. The coated plates were incubated in a humidified chamber for 16 to $20 \mathrm{~h}$ at $28^{\circ} \mathrm{C}$, and the diameter of the blue zone surrounding each spot was measured. To quantify the extracted AHL, different amounts of synthetic 3-oxo-C6-HSL were also spotted on each plate, and a standard curve was obtained by plotting the $\log _{10}$ pmol against the diameter of the zone of $\beta$ galactosidase activity.

\section{Measurement of GFP fluorescence.}

$P$. syringae cells grown in KBB were collected by centrifugation at $10,000 \times g$ for $2 \mathrm{~min}$, were washed and were resuspended in a final volume of $4 \mathrm{ml}$ of $10 \mathrm{mM}$ potassium phosphate buffer, $\mathrm{pH} 7.0$, as in previous studies (Joyner and Lindow 2000). Fluorescence measurements were made in a fluorometer (Model TD-700; Turner Designs, Sunnyvale, CA, U.S.A.) with an excitation wavelength of $390 \mathrm{~nm}$ and an emission wavelength of 510 to $700 \mathrm{~nm}$. The fluorometer was calibrated using a solid standard ( 350 to $700 \mathrm{~nm}$ ), according to the manufacturer's instructions. The fluorescence of each sample was normalized for the number of cells present that were estimated from the turbidity of the cell suspension $(\lambda=600 \mathrm{~nm})$ and a standard curve relating turbidity to culturable cells per $\mathrm{ml}$.

\section{Plant inoculations.}

Cells of $P$. syringae strains were grown on $\mathrm{KB}$ for two days at $28^{\circ} \mathrm{C}$, were removed from plates, and were resuspended in 10 $\mathrm{ml}$ of $10 \mathrm{mM}$ potassium phosphate buffer, $\mathrm{pH}$ 7.0. The cell suspension was diluted with $1 \mathrm{mM}$ potassium phosphate buffer, $\mathrm{pH}$ 7.0 , to yield a suspension containing $10^{6} \mathrm{CFU} / \mathrm{ml}$, as in previous studies (Lindow 1993; Wilson et al. 1999). Pots of 2-week-old bean plants (Phaseolus vulgaris cv. Bush Blue Lake 274) containing 10 plants per pot were spray-inoculated to wetness, as in other studies (Brandl et al. 2001; Wilson et al. 1999). Immediately after inoculation, the replicate pots of plants used for each treatment were placed in a chamber that maintained a high relative humidity (approximately $>80 \%$ ) for $48 \mathrm{~h}$ at 26 to $28^{\circ} \mathrm{C}$. Ten individual leaves were sampled at random for every treatment. All pots were then transferred to a growth chamber that maintained a low relative humidity (approximately $<40 \%$ ) for $48 \mathrm{~h}$ at $28^{\circ} \mathrm{C}$ with constant illumination. For each treatment, 15 individual leaves were sampled at random. To determine the population sizes of epiphytic bacteria, each leaf was immersed individually in $20 \mathrm{ml}$ of washing buffer $(100 \mathrm{mM}$ potassium phosphate buffer [pH 7.0] containing $0.1 \%$ bacto-peptone [Difco]) in 25mm-diameter test tubes. The test tubes were then sonicated in an ultrasonic bath for $7 \mathrm{~min}$ and were vortexed briefly, as previously described (O'Brien and Lindow 1989). Serial dilutions of each sample were plated on KB containing rifampicin and 12.5 $\mu \mathrm{g}$ of benomyl per ml using a spiral plater (Model D; Spiral Systems, Inc. Cincinnati, OH, U.S.A.), as in previous studies (Lindow 1998).

\section{ACKNOWLEDGMENTS}

The authors wish to thank G. A. Beattie and S. Lioret for the generation and initial identification of Tn5 mutants, J.-M. Monier for initial charac- 
terization of $P$. syringae mutant 538, and R. Binder from the United States Department of Agriculture Western Regional Research Center (Albany, CA) for kindly providing synthetic 3-oxo-hexanoyl homoserine lactone. We also thank K. DeAngelis, G. Dulla, K. L. Newman, G. Wichman, and M. Wilson for critically reading the manuscript. This work was supported by a grant from the Torrey Mesa Research Institute, Syngenta Research and Technology, San Diego, CA, and by a Ford Foundation Postdoctoral Fellowship to B. Quiñones.

\section{LITERATURE CITED}

Albus, A. M., Pesci, E. C., Runyen-Janecky, L. J., West, S. E., and Iglewski, B. H. 1997. Vfr controls quorum sensing in Pseudomonas aeruginosa. J. Bacteriol. 179:3928-3935.

Andersen, G. L., Beattie, G. A., and Lindow, S. E. 1998. Molecular characterization and sequence of a methionine biosynthetic locus from Pseudomonas syringae. J. Bacteriol. 180:4497-4507.

Ausubel, F. M., Brent, R., Kingston, R. E., Moore, D. D., Seidman, J. G., Smith, J. A., and Struhl, K. 1995. Current Protocols in Molecular Biology. John Wiley \& Sons, Inc., New York.

Bainton, N. J., Stead, P., Chabra, S. R., Bycroft, B. W., Salmond, G. P., Stewart, G. S., and Williams, P. 1992. N-(3-oxohexanoyl)-L-homoserine lactone regulates carbapenem antibiotic production in Erwinia carotovora. Biochem. J. 288:997-1004.

Beattie, G. A., and Lindow, S. E. 1994. Comparison of the behavior of epiphytic fitness mutants of Pseudomonas syringae under controlled and field conditions. Appl. Environ. Microbiol. 60:3799-3808.

Beattie, G. A., and Lindow, S. E. 1999. Bacterial colonization of leaves: A spectrum of strategies. Phytopathology 89:353-359.

Beck von Bodman, S., and Farrand, S. K. 1995. Capsular polysaccharide biosynthesis and pathogenicity in Erwinia stewartii require induction by an $N$-acylhomoserine lactone autoinducer. J. Bacteriol. 177:50005008.

Beck von Bodman, S., Majerczak, D. R., and Coplin, D. L. 1998. A negative regulator mediates quorum-sensing control of exopolysaccharide production in Pantoea stewartii subsp. stewartii. Proc. Natl. Acad. Sci. U.S.A. 95:7687-7692.

Brandl, M. T., Quiñones, B., and Lindow, S. E. 2001. Heterogeneous transcription of an indoleacetic acid biosynthetic gene in Erwinia herbicola on plant surfaces. Proc. Natl. Acad. Sci. U.S.A. 98:3454-3459.

Cha, C., Gao, P., Chen, Y.-C., Shaw, P. D., and Farrand, S. K. 1998. Production of acyl-homoserine lactone quorum-sensing signals by gramnegative plant-associated bacteria. Mol. Plant. Microbe Interact. 11:1119-1129.

Chancey, S. T., Wood, D. W., and Pierson, L. S., III. 1999. Two-component transcriptional regulation of $\mathrm{N}$-acyl-homoserine lactone production in Pseudomonas aureofaciens. Appl. Environ. Microbiol. 65:22942299.

Chatterjee, A., Cui, Y., and Chatterjee, A. K. 2002. RsmA and the quorumsensing signal, $N$-[3-oxohexanoyl]-L-homoserine lactone, control the levels of rsmB RNA in Erwinia carotovora subsp. carotovora by affecting its stability. J. Bacteriol. 184:4089-4095.

Chugani, S. A., Whiteley, M., Lee, K. M., D’Argenio, D., Manoil, C., and Greenberg, E. P. 2001. QscR, a modulator of quorum-sensing signal synthesis and virulence in Pseudomonas aeruginosa. Proc. Natl. Acad. Sci. U.S.A. 98:2752-2757.

Cohen, M. F., Meeks, J. C., Cai, Y. A., and Wolk, C. P. 1998. Transposon mutagenesis of heterocyst-forming filamentous cyanobacteria. Pages 317 in: Methods in Enzymology. Academic Press, San Diego, CA, U.S.A.

de Kievit, T. R., and Iglewski, B. H. 2000. Bacterial quorum sensing in pathogenic relationships. Infect. Immun. 68:4839-4849.

de Kievit, T., Seed, P. C., Nezezon, J., Passador, L., and Iglewski, B. H. 1999. RsaL, a novel repressor of virulence gene expression in Pseudomonas aeruginosa. J. Bacteriol. 181:2175-2184.

Devine, J. H., Shadel, G. S., and Baldwin, T. O. 1989. Identification of the operator of the lux regulon from the Vibrio fischeri strain ATCC7744. Proc. Natl. Acad. Sci. U.S.A. 86:5688-5692.

Diggle, S. P., Winzer, K., Lazdunski, A., Williams, P., and Cámara, M. 2002. Advancing the quorum in Pseudomonas aeruginosa: MvaT and the regulation of $\mathrm{N}$-acylhomoserine lactone production and virulence gene expression. J. Bacteriol. 184:2576-2586.

Dumenyo, C. K., Mukherjee, A., Chun, W., and Chatterjee, A. K. 1998. Genetic and physiological evidence for the production of $\mathrm{N}$-acyl homoserine lactones by Pseudomonas syringae pv. syringae and other fluorescent plant pathogenic Pseudomonas species. Eur. J. Plant Pathol. 104:569-582.

Elasri, M., Delorme, S., Lemanceau, P., Stewart, G., Laue, B., Glickmann, E., Oger, P. M., and Dessaux, Y. 2001. Acyl-homoserine lactone pro- duction is more common among plant-associated Pseudomonas spp. than among soilborne Pseudomonas spp. Appl. Environ. Microbiol. 67:1198-1209.

Fuqua, C., Parsek, M. R., and Greenberg, E. P. 2001. Regulation of gene expression by cell-to-cell communication: Acyl-homoserine lactone quorum sensing. Annu. Rev. Genet. 35:439-468.

Gray, K. M., and Garey, J. R. 2001. The evolution of bacterial LuxI and LuxR quorum sensing regulators. Microbiology 147:2379-2387.

Hillen, W., and Berens, C. 1994. Mechanisms underlying expression of Tn10 encoded tetracycline resistance. Annu. Rev. Microbiol. 48:345369.

Hirano, S. S., and Upper, C. D. 2000. Bacteria in the leaf ecosystem with emphasis on Pseudomonas syringae: A pathogen, ice nucleus, and epiphyte. Microbiol. Mol. Biol. Rev. 64:624-653.

Hrabak, E. M., and Willis, D. K. 1993. Involvement of the lemA gene in production of syringomycin and protease by Pseudomonas syringae pv. syringae. Mol. Plant. Microbe Interact. 6:368-375.

Jones, S., Yu, B., Bainton, N. J., Birdsall, M., Bycroft, B. W., Chhabra, S. R., Cox, A. J., Golby, P., Reeves, P. J., Stephens, S. et al. 1993. The lux autoinducer regulates the production of exoenzyme virulence determinants in Erwinia carotovora and Pseudomonas aeruginosa. EMBO J. 12:2477-2482.

Joyner, D. C., and Lindow, S. E. 2000. Heterogeneity of iron bioavailability on plants assessed with a whole-cell GFP-based bacterial biosensor. Microbiology 146:2435-2445.

King, E. O., Ward, M. K., and Raney, D. E. 1954. Two simple media for the demonstration of pyocyanin and fluorescein. J. Lab. Clin. Med. 44:310-307.

Kinscherf, T. G., and Willis, D. K. 1999. Swarming by Pseudomonas syringae $\mathrm{B} 728$ a requires gacS (lemA) and gacA but not the acyl-homoserine lactone biosynthetic gene ahlI. J. Bacteriol. 181:4133-4136.

Kitten, T., Kinscherf, T. G., McEvoy, J. L., and Willis, D. K. 1998. A newly identified regulator is required for virulence and toxin production in Pseudomonas syringae. Mol. Microbiol. 28:917-929.

Latifi, A., Foglino, M., Tanaka, K., Williams, P., and Lazdunski, A. 1996. A hierarchical quorum-sensing cascade in Pseudomonas aeruginosa links the transcriptional activators LasR and RhIR (VsmR) to expression of the stationary-phase sigma factor RpoS. Mol. Microbiol. 21:1137-1146.

Laville, J., Voisard, C., Keel, C., Maurhofer, M., Defago, G., and Haas, D. 1992. Global control in Pseudomonas fluorescens mediating antibiotic synthesis and suppression of black root rot of tobacco. Proc. Natl. Acad. Sci. U.S.A. 89:1562-1566.

Ledgham, F., Soscia, C., Chakrabarty, A., Lazdunski, A., and Foglino, M. 2003. Global regulation in Pseudomonas aeruginosa: The regulatory protein $\mathrm{AlgR} 2(\mathrm{AlgQ})$ acts as a modulator of quorum sensing. Res. Microbiol. 154:207-213.

Lindow, S. E. 1993. Novel method for identifying bacterial mutants with reduced epiphytic fitness. Appl. Environ. Microbiol. 59:1586-1592.

Lindow, S. E., Desurmont, C., Elkins, R., McGourty, G., Clark, E., Brandl, M.T. 1998. Occurrence of indole-3-acetic acid-producing bacteria on pear trees and their association with fruit russet. Phytopathology 88:1149-1157.

Loh, J., Pierson, E. A., Pierson, L. S., III, Stacey, G., and Chatterjee, A. 2002. Quorum sensing in plant-associated bacteria. Curr. Opin. Plant Biol. 5:285-290.

Loper, J. E., and Lindow, S. E. 1987. Lack of evidence for in situ fluorescent pigment production by Pseudomonas syringae pv. syringae on bean leaf surfaces. Phytopathology 77:1449-1454.

Manefield, M., and Turner, S. L. 2002. Quorum sensing in context: Out of molecular biology and into microbial ecology. Microbiology 148:37623764.

McGowan, S., Sebaihia, M., Jones, S., Yu, B., Bainton, N., Chan, P. F., Bycroft, B., Stewart, G. S., Williams, P., and Salmond, G. P. 1995. Carbapenem antibiotic production in Erwinia carotovora is regulated by CarR, a homologue of the LuxR transcriptional activator. Microbiology 141:541-550.

Miller, M. B., and Bassler, B. L. 2001. Quorum sensing in bacteria. Annu. Rev. Microbiol. 55:165-199.

Miller, W. G., Leveau, J. H. J., and Lindow, S. E. 2000. Improved $g f p$ and inaZ broad-host-range promoter-probe vectors. Mol. Plant. Microbe Interact. 13:1243-1250.

Monier, J.-M., and Lindow, S. E. 2003. Differential survival of solitary and aggregated bacterial cells promotes aggregate formation of leaf surfaces. Proc. Natl. Acad. Sci. U.S.A. 100:15977-15982.

Monier, J.-M., and Lindow, S. E. 2004. Frequency, size and localization of bacterial aggregates on bean leaf surfaces. Appl. Environ. Microbiol. 70:345-355.

Morris, C. E., Monier, J.-M., and Jacques, M.-A. 1997. Methods for observing microbial biofilms directly on leaf surfaces and recovering 
them for isolation of culturable microorganisms. Appl. Environ. Microbiol. 63:1570-1576.

Morris, C. E., Monier, J.-M., and Jacques, M.-A. 1998. A technique to quantify the population size and composition of the biofilm component in communities of bacteria in the phyllosphere. Appl. Environ. Microbiol. 64:4789-4795.

O'Brien, R. D., and Lindow, S. E. 1989. Effect of plant species and environmental conditions on epiphytic population sizes of Pseudomonas syringae and other bacteria. Phytopathology 79:619-627.

Pearson, J. P. 2002. Early activation of quorum sensing. J. Bacteriol. 184:2569-2571.

Pessi, G., Williams, F., Hindle, Z., Heurlier, K., Holden, M. T., Cámara, M., Haas, D., and Williams, P. 2001. The global posttranscriptional regulator RsmA modulates production of virulence determinants and $\mathrm{N}$ acylhomoserine lactones in Pseudomonas aeruginosa. J. Bacteriol. 183:6676-6683

Pierson, L. S. I., Wood, D. W., and Beck von Bodman, S. 1999. Quorum sensing in plant-associated bacteria. Pages 101-115 in: Cell-Cell Signaling in Bacteria. American Society for Microbiology, Washington, D.C.

Piper, K. R., Beck von Bodman, S., and Farrand, S. K. 1993. Conjugation factor of Agrobacterium tumefaciens regulates Ti plasmid transfer by autoinduction. Nature 362:448-450.

Pirhonen, M., Flego, D., Heikinheimo, R., and Palva, E. T. 1993. A small diffusible signal molecule is responsible for the global control of virulence and exoenzyme production in the plant pathogen Erwinia carotovora. EMBO (Eur. Mol. Biol. Organ.) J. 12:2467-2476.

Reimmann, C., Beyeler, M., Latifi, A., Winteler, H., Foglino, M., Lazdunski, A., and Haas, D. 1997. The global activator GacA of Pseudomonas aeruginosa PAO positively controls the production of the autoinducer $\mathrm{N}$-butyryl-homoserine lactone and the formation of the virulence factors pyocyanin, cyanide, and lipase. Mol. Microbiol. 24:309-319.

Rich, J. J., Kinscherf, T. G., Kitten, T., and Willis, D. K. 1994. Genetic evidence that the gacA gene encodes the cognate response regulator for the lemA sensor in Pseudomonas syringae. J. Bacteriol. 176:7468-7475.

Rouse, D. I., Nordheim, E. V., Hirano, S. S., and Upper, C. D. 1985. A model relating the probability of foliar disease incidence to the population frequencies of bacterial plant pathogens. Phytopathology 75:505509.

Sambrook, J., Fritsch, E. F., and Maniatis, T. 1989. Molecular Cloning: A Laboratory Manual. 2nd ed. Cold Spring Harbor Laboratory Press, Cold Spring Harbor, NY, U.S.A.

Schuster, M., Lostroh, C. P., Ogi, T., and Greenberg, E. P. 2003. Identification, timing, and signal specificity of Pseudomonas aeruginosa quorum-controlled genes: A transcriptome analysis. J. Bacteriol. 185:20662079.

Shaw, P. D., Ping, G., Daly, S. L., Cha, C., Cronan, J. E., Jr., Rinehart, K. L., and Farrand, S. K. 1997. Detecting and characterizing $N$-acyl-homoserine lactone signal molecules by thin-layer chromatography. Proc. Natl. Acad. Sci. U.S.A. 94:6036-6041.
Staskawicz, B., Dahlbeck, D., Keen, N., and Napoli, C. 1987. Molecular characterization of cloned avirulence genes from race 0 and race 1 of Pseudomonas syringae pv. glycinea. J. Bacteriol. 169:5789-5794.

Trieu-Cuot, P., and Courvalin, P. 1983. Nucleotide sequence of the Streptococcus faecalis plasmid gene encoding the 3'5"-aminoglycoside phosphotransferase type III. Gene 23:331-341.

Von Bodman, S. B., Bauer, W. D., and Coplin, D. L. 2003. Quorum sensing in plant-pathogenic bacteria. Annu. Rev. Phytopathol. 41:455-482.

Wagner, V. E., Bushnell, D., Passador, L., Brooks, A. I., and Iglewski, B. H. 2003. Microarray analysis of Pseudomonas aeruginosa quorumsensing regulons: Effects of growth phase and environment. J. Bacteriol. 185:2080-2095.

Watson, B., Currier, T. C., Gordon, M. P., Chilton, M. D., and Nester, E. W. 1975. Plasmid required for virulence of Agrobacterium tumefaciens. J. Bacteriol. 123:255-264.

Whitehead, N. A., Barnard, A. M., Slater, H., Simpson, N. J., and Salmond, G. P. 2001. Quorum-sensing in gram-negative bacteria. FEMS (Fed. Eur. Microbiol. Soc.) Microbiol. Rev. 25:365-404.

Whiteley, M., Lee, K. M., and Greenberg, E. P. 1999. Identification of genes controlled by quorum sensing in Pseudomonas aeruginosa. Proc. Natl. Acad. Sci. U.S.A. 96:13904-13909.

Whiteley, M., Parsek, M. R., and Greenberg, E. P. 2000. Regulation of quorum sensing by RpoS in Pseudomonas aeruginosa. J. Bacteriol. 182:4356-4360.

Willis, D. K., Hrabak, E. M., Rich, J. J., Barta, T. M., Lindow, S. E., and Panopoulos, N. J. 1990. Isolation and characterization of a Pseudomonas syringae pv. syringae mutant deficient in lesion forming ability on bean. Mol. Plant. Microbe Interact. 3:149-156.

Wilson, M., Hirano, S. S., and Lindow, S. E. 1999. Location and survival of leaf-associated bacteria in relation to pathogenicity and potential for growth within the leaf. Appl. Environ. Microbiol. 65:1435-1443.

Wolk, C. P., Cai, Y., and Panoff, J. M. 1991. Use of a transposon with luciferase as a reporter to identify environmentally responsive genes in a cyanobacterium. Proc. Natl. Acad. Sci. U.S.A. 88:5355-5359.

Wood, D. W., and Pierson, L. S., III. 1996. The phzI gene of Pseudomonas aureofaciens 30-84 is responsible for the production of a diffusible signal required for phenazine antibiotic production. Gene 168:49-53.

Wood, D. W., Gong, F., Daykin, M. M., Williams, P., and Pierson, L. S., III. 1997. $N$-acyl-homoserine lactone-mediated regulation of phenazine gene expression by Pseudomonas aureofaciens 30-84 in the wheat rhizosphere. J. Bacteriol. 179:7663-7670.

Zhang, Z., and Pierson, L. S., III. 2001. A second quorum-sensing system regulates cell surface properties but not phenazine antibiotic production in Pseudomonas aureofaciens. Appl. Environ. Microbiol. 67:43054315.

Zhu, J., and Winans, S. C. 2001. The quorum-sensing transcriptional regulator TraR requires its cognate signaling ligand for protein folding, protease resistance, and dimerization. Proc. Natl. Acad. Sci. U.S.A. 98:1507-1512. 